\title{
The MasterChef Journey to Brain through Stomach: Food as Transnational Capital
}

\author{
Diganta Bhattacharya \\ Assistant Professor, Department of English, Sundarvan Mahavidyalaya, West Bengal $\mathcal{E}$ \\ Research Scholar, Presidency University. Email: diganta.bhat@gmail.com
}

\begin{abstract}
The notion of 'capital' being fluid, it comfortably lends itself to a multiplicity of interpretive-analytical frameworks that involve anything that can be 'cashed in'. The significance of food in its myriad manifestations and reimagining-s can barely be overstated as it not only is irreplaceable due to biologicalgustatory function but also due to the way people connect with it culturally, domestically, ethnically and personally. A 1990 show created by Franc Roddam in UK was essentially resuscitated, reconceived and redeveloped in Australia in 2009 and the rest, literally, is history. Masterchef has become a culinary phenomenon like no other, has got its iterations across several continents and has essentially reimagined how 'food' is approached as well as conceptualized. A steep competitive framework and the time-tested format of a reality show can be argued to be two of the most significant reasons of its immense success which is apparent from its extensive viewership. This essay seeks to interrogate a format that, admittedly competitive and eclectic, has successfully found out a method of manipulating consumer choices through a sort of strategic representation. By no means a straightforward Marxist critique of capital-flows as operative in such sites that are determined by different modalities of choice-based resource-utilization in an age of unprecedented interpenetration of the public and the private life, this study also strives to be a close 'reading' of the reality show 'Masterchef Australia' and the subtle ways it has continued to impact food culture around the world including India since 2009.
\end{abstract}

Keywords: Food, MasterChef, Australia, Culture, Capital, Pluralistic Democracy, Transnational, Body, Individual, choice, Economy, Reality show, Digital Behaviour

\section{Eating, historically and culturally conceived}

The sheer absence of consensus on what should be called 'a good plate of food' chiefly has to do with the absolutely numerous as well as varied socio-cultural realities that have been instrumental in the production of such. A particular food-item can scarcely be approached in separation from the reality that rendered it possible, and cultural provenance plays such an absolutely significant part in the overall 'experience' of a specific dish that oftener-than-not it is that which becomes the focal point while appreciating a dish; even more so than the item itself. This should remind any food-enthusiast of what the recently-deceased Anthony Bourdain had to observe:

"Meals make the society, hold the fabric together in lots of ways that were charming and interesting and intoxicating to me. The perfect meal, or the best meals, occur in a context that frequently has very little to do with the food itself."

Due to the unique geographical associations and histories and ethnographic realities that a particular dish is always accompanied with, it always has its own story to tell, its individual narrative that justifies its existence as well as legacy. But 'legacy' is not static or a hermetically (C) AesthetixMS 2020. This Open Access article is published under a Creative Commons Attribution Non-Commercial 4.0 International License (http://creativecommons.org/licenses/by-nc/4.0/), which permits non-commercial re-use, distribution, and reproduction in any medium, provided the original work is properly cited. For citation use the DOI. For commercial re-use, please contact editor@rupkatha.com. 
sealed concept, 'legacy' is in constant need of reinvention: the narrative that accompanies a particular dish desperately requires re-telling so as to make sense in an economy that increasingly seeks to find a way to the particular, idiosyncratic and individual from the general, massproduced and typical. ${ }^{\text {ii }}$

The title of this essay has replaced 'heart' with 'brain' and with good reason. Food, in a socioeconomic set-up where culinary shows like MasterChef matter, happens to be determined by factors like eclecticism, optimal choices and affordability. Choices are not necessarily reflective of individual predilections that can be traced back to fond memories of hitherto-consumed fooditems; but instead may as well be consequences of exposure to gastronomic novelties explored by international experts keen on pushing the boundaries of culinary possibilities. In a strange turn of events, cooking has become as much about performance as eating; in South Korea, as for example, people pay hefty amount of money to see people eat, even online, a practice called 'mukbang' on which BBC has a documentary. iii As a site of performativity that encapsulates a multiplicity of intersecting fields ${ }^{\mathrm{iv}}$, the concept of eating, thus, has been 'liberated' in a sense, in that it is no longer a biophysical process, but rather a dense locus where several influences converge to generate a layered text, and hence is as much a 'production' as the manufacturing processes that rendered it possible. 'Eating' in the process becomes a condensed, objectified and most importantly, strategic performance that is constantly redefined and reevaluated by signifiers from different and oftener-than-not mutually exclusive cultural or methodological fields. ${ }^{v}$ It is ultimately this significant moment of field-intersection that, I propose, culinary shows like MasterChef seek to arrest and represent. The attributes of 'fine dining', as categorically inventoried in The Art of Cuisine by the French entrepreneur Antoine Beauvilliers back in $1782^{\mathrm{vi}}$, have remained all or at least most of the following: gourmet food, vintage wine, refined service, an elegant place setting and a sumptuous location. Communal sharing of food and festive cooking have been a part of all traditional cultures ${ }^{\text {vii }}$; but the globally accepted idea of how eating can be done 'in style', also draws heavily upon the French conceptualizations on haute cuisine and nouvelle cuisine that included, among other things, "self-conscious reflexivity, regionalism (the decentralization and relativization of techniques, materials, and styles); exoticism (the juxtaposition and incorporation of foreign elements on equal footing with native material)." ${ }^{\text {viii }}$ It is indeed easy to figure the extent to which such an arrangement is heavily reliant upon stratified capital. Like any performance that aspires to be a spectacle in itself and that requires a dedicated clan of spectators, in a competitive culinary show 'eating' along with its paraphernalia of marketing, resource-gathering, mise en place, planning a dish, methodical and tactical execution, catering, 'tasting', formal voting and an extravagant judgment, - is strategically metamorphosed into a spectacle with its own dedicated host of viewers who understand the subtle rules of this elaborate game. ${ }^{\text {ix }}$

\section{MasterChef as embodied cultural capital/Culture of capital}

As a cooking competition to be aired on television, MasterChef was conceived back in 1990 in the UK, but had to wait for a long stretch of 19 years to receive an official 'restoration' into its present format in 2009 in Australia. ${ }^{\mathrm{X}}$ The show has been a recipient of multiple awards in Australia including the most prestigious Logie Awards; ${ }^{x i}$ but most importantly, it has been a huge success in the Australian television with more than four million viewers for the season finale of the first Masterchef in $2009^{\mathrm{xii}}$, an astounding figure considering the entire volume of Australian population in 2009 was only 21 million. ${ }^{\text {xii }}$ David Penberthy attributes the reason for this widespread acceptance of this show to "a simple reason" which is, in his own words, "instead of 
making heroes out of people you would do anything to avoid, it celebrated people you'd be happy to have as friends, or proud to have as part of your family." competition from emerging shows like Australian Ninja Warrior, MasterChef has lost significant amount of its metro viewership. ${ }^{\mathrm{x}}$ But considering the key demographic it still attracts, the accomplishment of million-strong metro viewership that it continues to sustain has been referred to as a "remarkable achievement" by Beverley McGarvey, ${ }^{\text {xvi }}$ the chief content officer of Network Ten, the official broadcaster and custodian of MasterChef since 2009. Keeping in view its persistent followers and a thriving enthusiasm for the show, Network Ten more than doubled the prize money with an announcement in the 2014 iteration of the show ${ }^{\text {xvii }}$ where the winner could take home a hefty 2.5 hundred thousand dollars and an attractive book deal which has proved to be an enormously successful venture considering that fact that Coles, MasterChefs major sponsor, had reported a 1,400 \% spike in the sales of products used in MasterChef recipes ${ }^{\text {xviii }}$ back in 2013. With 213.6 thousand followers in Twitter ${ }^{\mathrm{xix}}$ and 1.76 million followers on Facebook ${ }^{\mathrm{xx}}$, the show has not only become a household name; it has come to embody the distinctive food culture of Australia and therefore can be considered a representative media- imprint that steadfastly registers Australia's lifestyle as one that belongs to the first world, the global north. ${ }^{\text {xxi }}$

There are only a handful ways in which a state that professes itself to be modern and democratic seeks to promote its cosmopolitan, pluralistic inclusivity and that "gateway function", so appositely referred to by Audrey Yue as he explains how Singapore Tourism has attempted to achieve it, is best served by "multicultural eating", among other things. ${ }^{\text {xii }}$ A culture that has adopted liberal multiculturalism as a normative concept must allow associated ideas of 'official multiculturalism ${ }^{\text {xxiii }}$ in places of discursive intersection, such as public pedagogy. ${ }^{\text {xxiv }}$ Incipient in this fulcrum of cosmopolitan multiculturalism are the theoretical possibilities of a well-defined and mapped-out 'discourse on food' which can, and does in fact assume the role of a key constitutive component that renders possible sites of intersubjective engagements. The act of 'eating' is both personal/subjective and ceremonial/objective in nature and in each case, participation in some sort of transactional economy is involuntary and obligatory. The collusion (used to mean complicity, involvement but as Fowler has observed, the idea of illegality, underhandedness in almost always implicated in the use of this word ${ }^{\mathrm{xxv}}$ ) and injection of massive yet targeted capital in the entire culinary framework is taken for granted, and to give an idea of the swelling 'massiveness' of the capital invested in food and related industries, according to a report compiled back in 2015, for the financial year 2014 the food and beverage sector represented approximately $16.7 \%$ to $20 \%$ of the world economy. ${ }^{\text {xxi }}$ This was a huge number, amounting to a whopping 15.1 trillion US Dollar, ${ }^{\text {xvii }}$ a sum that definitely has significantly increased during the last three and a half years. To talk about food, in other words, is to talk about capital and the way(s) it can be traced through a dizzying multiplicity of conduits that make what is understood as 'food industry' possible.

There is one, absolutely vital aspect to consider, though. Despite being defined by capital that is consolidated, dispersed as well as stratified; the concept of food, unlike other sites of capitaldistribution, cannot be restricted as its essential interpersonal and cultural significations are always too manifest and unavoidable. This is apparent in the way food, along with its ideational associations, is instrumental in projecting structures of identity: The kitchen or the food-counter functions not only as a way to achieve financial independence in a socially recognized and 'respected' fashion; ;xviii through the enshrinement of a self-aware locatedness in an interlinked network of systematized conceptual frameworks, it becomes "a highly condensed social fact."xxix 


\section{Food, Representation, Consumption, Subjectivity}

The inclusive term 'foodscape', through its dual enshrinement of diversified capital and cultural identities, implies not only the condition of choices related to cuisines and consumption, but also a fluid site of interpersonal intersections which is constantly in a process of being defined and redefined. Specific dishes with unique ethnic tags are, consequently, less 'novelty items' and more pathways of accessing other equally-valid as well as attractive sites for encroachment of capital. Establishing the 'salability' of an item imported, in a way, from another culture not only determines the use-value of that particular object; as it is registered in the existing consumernetwork its uncomfortable dissimilarity is effectively co-opted in the known scheme of things, hence 'normalized. ${ }^{\text {xxx }}$ Quite like other reality shows, what MasterChef has been able to achieve is the 'normalization' of the processes and decisions concerning 'juridification' that are necessarily germane to elaborate competitive scenarios projected as game-sequences, ${ }^{\text {xxi }}$ and the way the show has admirably done it is through strategic framing of such sequences. This 'strategic framing' is essential for two highly significant reasons:

One, an ideal consumer is a tailor-made, customized subject who has to be, in a certain sense, constructed, coaxed into existence. ${ }^{x x i i}$ Apparently, the surveillance-mode of a reality show is effective only because its 'norms' are mutually agreed-upon as in a game, and in this sense the subjects 'construct' themselves into ideal participants who, in turn, produce ideal consumers by showcasing 'normative' behavioural patterns vis-à-vis resources and consumption. ${ }^{\text {xxiii }}$

Two, strategic framing ensures a smooth 'packaging' which is essential if something has to be made into an exquisite, gratifying object that can be sold. MasterChef makes absolutely sure, as for example, that the cooking-ingredients that are used are nothing but the most perfect specimens, the utensils employed are supremely expensive and unrealistically shiny, without a single smudge; even the uncomfortable reality of a bloody finger is denied a straight shot in case a contestant accidentally hurts him/herself. 'Cooking' is neatly packaged and represented as a completely airy, clean, almost abstract performance where 'perfection' is unattainable only through human incompetence.

Apart from the representation of an idealized 'competitor' who painstakingly abides by the preestablished instructions and wins or loses 'fairly', a reality show like MasterChef successfully generates in a sense, object-fetishization. Commodity-fetishism is always a visual event; it has to do with the

“...social relation of objects which exists outside (the labourers, the competitors in this context). It is a particular social relation between men themselves which in their eyes assumes a phantasmagorical form of a relation between things. ... This is what I call fetishism; it attaches itself to the products of labour as soon as they are produced as commodities, and it is therefore inseparable from the production of commodities. ${ }^{x x i v}$

It is through participating in this interactional framework dominated by visuals that the intended 'subject' is formed, as subject is the 'materialization' of productive relations that renders the production-consumption cycle possible. ${ }^{\mathrm{xxv}}$

Embedded in a methodical representational framework, objects-as-presented onscreen are projected as part of a narrative, and to achieve the 'effect' proper they are meticulously accorded an emotional content. Acquisition of those objects, goods and services then signifies and expresses emotional commitment, and the expenditure involved equates to a popular, normative understanding of 'love' and 'care' and that desired 'happy ending' that blissfully offers a secured sense of closure. All these notions, carefully crafted and tactically represented onscreen are 
operated and exploited by a 'market' that is keenly sensitive about the essential profitability of everything that requires investment of any sort. It is this specular, ocularcentric aspect of strategic representations of objects that June Deery identifies as a kind of psychological reflex which she christens "Wealth Voyeurism."xxxvi Wealth Voyeurism which is a kind of object fetishism, capitalizes on how through representational quirks an object is transitioned into an event, satisfying the pivotal purpose of what she calls "featured product placement."xxxvii The representations of ethnic dishes or those that are supposedly evocative of childhood-familial connections or are explorations of a 'personal foodscape' are always encouraged to arrest that elusive instant when the object and 'business' of a competition metamorphoses into a significant moment with an emotive impact. Success in these 'tasks' (the famous Invention Tests or Mystery Box Challenges) can only be achieved with creative and challenging twists; the parameters or 'norms' of the 'game' are continually manipulated so as to allow considerable modification of the 'traditional'. In this way, aspirant chefs aren't allowed to passively accept their fractured connections to their homeland but instead are stimulated to actively work to rebuild those connections so that they are more amenable to reinterpretations as well as reimagining-s in an economy governed by a specific kind of mobile capital. The 'investment' is as much monetary as it is inevitably emotional and sentimental. ${ }^{\text {xxviii }}$ This may explain why the show, despite premiering in England, hadn't been as successful internationally as it might have been when it first came on BBC in 1990. The show was essentially made to undergo drastic rearrangements in 2005 and 2008 to incorporate the easily-recognizable format of the MasterChef. Perhaps the most significant and effective representational move consists of the show's strategic projection of itself as a rollercoaster of emotions where contestants burst into tears for something as seemingly insignificant as a marginally-overcooked fish. A culinary show that promises to be a life-altering experience, is represented that way through a tried-and-tested method of packaging which is geared towards evoking specific sentimental and emotional responses to specific sequences. What have been immensely successful in the Australian version of this show are the exposition(s) of the familialdomestic connection that is inescapably inherent in the planning and execution of every dish, the ethno-cultural diversity informing the plurality of choices that are never forgotten and most importantly, the human element that is made to 'shine' with the paraphernalia of drama, emotions, tears and promises, even amidst all the glitz and glitter of Michelin-star restaurants, luxurious cuisine and celebrity chefs. As the remainder of this essay shall seek to illustrate, MasterChef Australia strategically utilizes as well as profits from an established idea of 'multicultural democracy' where ethnographic variables are not only accepted and celebrated; they are also rendered instrumental to the vigorous interplay of capital, so vital to the smooth functioning of a 'successful' democracy.

\section{Incorporating and Transcending Australian-ness, the vocabulary of consumption}

The composite, amalgamated demographic of urban, cosmopolitan Australia might offer a corrective to the European idea of a nation, comprising the notion of a singular, coherent and mapped-out space that doesn't like contesting ethnicities or a migrated population which might problematize one, comfortable, unopposed identity formation. This requirement to negotiate two different conceptualizations on nationhood has been a constant source of indecision about what should constitute the unique Australian identity, as is evident in Catriona Elder's remark:

"The fantasy of a clearly bounded and inviolable national space has underpinned many of the ideas that white Australians carry with them of what it means to be 'Australian'... Yet 'White Australia' is produced in terms of a triangulated relationship between white Australians, an 
internal Indigenous Other and an external non-white Other...The unity is always a fiction of course, because the "us" on the inside is itself always differentiated."xxxix

Intentional disavowal of those that cannot claim inclusion in an ethnically-restricted construct of 'white Australia'xl creates an actively negative space for smooth, unhindered flow of capital in a market economy that seeks penetration into ever-growing, ever-expanding 'target' consumers. In one way, then, cosmopolitan plurality and ethnic inclusivity are two significant prerequisites of and for a consumer-oriented capitalism. Approached from this perspective, strategic capital creates the possibility of transactional frameworks that engender space-s of mutually agreed-upon mechanisms pertaining to daily life, practices as well as choices. This is of absolute significance as it represents what Russ Castronovo argues to be the 'uncertain', liminal spaces that afford the possibility for innumerable types of intersection or slippage that can be conceived as "a theoretical space (that) provides commentators with a frontier of alternative identities fortuitously disconnected from antecedents of predation and exploitation." ${ }^{\prime}$ li Hence, these intersectional space-s can operate not necessarily as "sites of division", but rather "as the sutures of national cohesion, they can offer an imaginative topos for the articulation of "transcendent" ideals of racial supremacy and political unity". xlii What Castronovo implies here is of course politico-cultural 'meeting points' as well as 'overlaps' where differences are somewhat compromised and not always determined by financial choices. But consumerist decision-making options and choices have something unique about them, and that is their nomothetic, subject-independent aspect. The objective laws that govern and regulate modalities of financial behaviour and movements of capital predominantly operate without the mediation of ethnic predilections or presumptions and therefore it is possible to imagine an effective, cosmopolitan, co-operative framework that is chiefly organized and structured according to the laws of the 'market.' It is a crucial realization in so many ways as from this proposition it can be inferred that cleverly-manipulated and strategically-stratified capital can and do possess a significant purchase on cultural divisions and consequently, can surmount perceived differences. Food, and in extension the bulk of capital invested in methodically itemized food-items in terms of their ethnic origin are, therefore, among the few devices that can act as a kind of tangible cross-ethnic 'currency' or capital. Evidently, the significance of food in establishing specific identity-constructs can barely be overstated given its ubiquitous, universal presence and anthropological significance:

Food thus entwines intimately with much that makes a culture unique, binding taste and satiety to group loyalties. Eating habits both symbolize and mark the boundaries of cultures. Scholars and ordinary people alike have long seen food habits, both positively and negatively, as concrete symbols of human culture and identity. When we want to celebrate, or elevate, our own group, we usually praise its superior cuisine... we must explore (also) the symbolic power of food to reflect cultural or social affinities in moments of change or transformation. ${ }^{\text {xliii }}$

But 'food' conceived a strategic field of engagement not only registers ethnographic specificity, but also can create possibilities of overlapping-s. Such 'situations of interaction' are not necessarily invasive transgressions; instead, they can be perceived as nuanced negotiations with prefabricated and mutually-agreed upon norms, as in a game. Thus food creates possibilities of generating foodways that serve as those liminal, nodal points which allow for incessant, conciliatory dialogues across ethnicities which, in turn, are absolutely instrumental in maintaining the cosmopolitan inclusivity of a pluralistic society. These foodways are incrementally constructed choices that have been meticulously informed by food-as-represented on interactive mediums such as Facebook and similar social networking platforms. Hyperlinks, instant and archived feedbacks and reviews, interactive module that renders the process of 
gathering requisite information a thrilling and fun-filled activity-are all factors that make digital platform a more viable option for showcasing anything that can be 'consumed'. But they achieve more than that. A Facebook profile or forum is not a 'passive' medium in the way a TV show is; it allows an individual to define and characterize a specific choice as a more independent and therefore honest one. Facebook or any social networking site for that matter, creates a unique unbounded interpersonal space that not only traverses national or ethnic boundaries; through forging 'friendship' with another compatible individual, mutual trust is established concerning a specific show or product or item and that plays a key factor in determining consumer choices. ${ }^{\text {xliv }}$ Multiple factors that include components as wide-ranging and varied as innovative software interfaces that allow a more immersive, tempting onscreen experience vis-à-vis a specific product, adware and cookies and unsolicited pop-ups that continually barrage the user, feedbacks and rating-systems,- all contribute to the inception, maturation and execution of a particular choice. All these happen in an alternative space that effectively bypasses the restrictive folds of a traditional, corporeal business model that must abide by practicable limitations and hence digital marketing or even digital chatter about a consumer product represent a novel mechanism which contributes to the transnational pathways that capital so desperately seeks to explore and proliferate.

It is here, through a thorough understanding and intelligent representation of this mechanism ${ }^{\mathrm{xlv}}$ that MasterChef has been able to explore conciliatory, negotiated and catholic solutions to the allegories of difference that constantly plague a society which aspires towards inclusive cosmopolitanism in the true sense of the term. Capital is indeed the greatest leveler in a certain sense: it is that mode of negotiation which not only cuts across other divides but can also make its influence manifest across both the 'up-down' and the 'bottom up' trajectories. ${ }^{\text {xlvi }}$ This is evident in the way MasterChef Australia has traditionally challenged its contestants: a 'mystery box' or an 'invention test' can contain expensive gourmet items like blue cheese and Kobe beef, or it can contain leftovers from the domestic refrigerator. The show has thus successfully sought to arrest a wide range of regular kitchen-worries as well as their imaginative and clever 'solutions' that encapsulate varied financial and resource-related restrictions and practicalities that any sensible marketeer can ill afford to ignore. To make things more complex, these realistic situations, as unpredictable as they are, also vary significantly across the ethno-cultural spectrum.

Consumption behaviour, choices and standards, therefore, are socially and financially determined ethno-cultural phenomena that are constantly in a process of incessant change since the societal backdrop against which the nature of them is ultimately determined are constantly undergoing transformations on multiple levels as well. ${ }^{\text {xlvii }}$ This network of interrelatedness and interdependence unambiguously demonstrates a 'feedback process' between consumers and society with its continually evolving patterns of migration, increasing cosmopolitanism and the accompanying changes in income distribution which, ultimately, impact capital-allocation. An increasingly popular culture of 'Food Adventuring'xlviii has propelled people to be more eclectic, liberal as well as experimental with eating 'novel,' 'authentic,' 'exotic' and 'dangerous' ethnic foodstuff and that, in turn, has satisfied the consumer-spectator's perceived status distinction for which s/he can be made to expend considerable amount of money. The intrinsic necessity of a particular item notwithstanding, what really become instrumental are the ocular associations that transform a dish into an object of fascination. In an age of the 'sacralizing' of the body ${ }^{\text {xlix }}$ in terms of both the subject-as-site-of-consumption and the neoliberal tradition of the centrality of the individual and his independent and hence sacred decisions in a choice-based economy, the body accrues enormous significance as the location where(in) consumerist fantasies/intentions are 
embedded. Baudrillard anticipated this shift towards the choice of 'demonstration effect' and the instrumentality/performativity of the consumer's body in 'realizing' this capitalistic project:

The body is simply the finest of these psychically possessed, manipulated and consumed objects. But the main thing is that this narcissistic reinvestment, orchestrated as a mystique of liberation and accomplishment, is in fact always simultaneously an investment of an efficient, competitive, economic type. The body 'reappropriated' in this way is reappropriated first to meet 'capitalist' objectives: in other words, where it is invested, it is invested in order to produce a yield. The body is not reappropriated for the autonomous ends of the subject, but in terms of a normative principle of enjoyment and hedonistic profitability, in terms of an enforced instrumentality that is indexed to the code and the norms of a society of production and managed consumption. ${ }^{1}$

A contemporary reality show like MasterChef Australia that strategically represents food and its ethnic possibilities, hence has become, quite unsurprisingly, a specific mode of accessing transcultural and even trans-national pathways and it is extremely effective as it operates through two most effective, ubiquitous and obligatory means: the capital (in its several, multiplicitous iterations) and the body itself. The framework of choice-based, conscientiously 'encouraged' consumption has its own vocabulary that is able to cut across several apparently insurmountable divides and boundaries. The celebration of uninterrupted cosmopolitanism can be argued to be the apotheosis of this show. Its success will be ultimately measured in terms of the extent to which the show has been able to humanize this process.

\section{Notes}

${ }^{\mathrm{i}}$ Anthony Michael Bourdain (June 25, 1956 - June 8, 2018) is fondly remembered as one of the leading celebrity chefs of contemporary times. He was, simultaneously, author, travel documentarian, and television personality who starred in shows on the exploration of international food culture and the peculiar societal conditions that have been instrumental in the 'inception' of a dish. At the time of his death, he was continuing with the extremely popular Anthony Bourdain: Parts Unknown, a culinary show on CNN. This line is quoted from:

"16 unforgettable quotes about life and food from Anthony Bourdain”, Jacob Shamsian, thisisinsider.com.

http://www.thisisinsider.com/anthony-bourdain-quotes-2018-6, posted on $8^{\text {th }}$ June, 2018, accessed on $26^{\text {th }}$ June, 2018. Web.

ii This I think is a recognition of the inherent flaw of all objects that aspires to be regarded as an aestheticartistic object in an age dominated by ever-more-perfect means of simulation and mechanical production, inevitably leading to what Walter Benjamin pointed out as a lack of 'authenticity', and a carefully-developed normativity as regards how to confer the status of 'art' upon an object. But deliberations over this issue, howsoever intriguing, is not what this essay is about.

iii <http://www.bbc.com/news/av/world-asia-31146357/making-money-by-eating-online-in-south-korea> Published on 05. 02. 2015 and Accessed on 28.12.2017

${ }^{i v}$ Pierre Bourdieu's conceptualizations on field are instructive in this case as for Bourdieu a field is relatively autonomous within its boundaries and each field is dominated by specific manifestations of cultural capital that it so meticulously represents or utilizes. It appears that in food the cultural capital is lately undergoing a significant transition from the status of the embodied and objectified to that of the institutionalized where a food-item is not only located within a network of cultural and socio-financial interrelations but also potentially accrues a distinctive individuality that imparts an institutional validation to that item which, in 
the process, represents symbolic capital. A dish, in this sense, is not only manufactured, it is created. The former allusion to Walter Benjamin and the perceived crisis of artistic (in)authenticity in an era of mechanical reproducibility appears more contextual in this sense.

${ }^{\mathrm{v}}$ It should not be difficult to establish how that is: when a contestant uses principles of biochemistry to create a 'theatrical effect' in the presentation of a dish consisting of expensive components to represent a plate of food that, purportedly, is supposed to represent a reimagined version of a dish that s/he had been fond of in childhood, several such fields of influence can be seen to be 'at work', as it were.

${ }^{v i}$ Originally published in French as L'art du Cuisinier, a digital copy of which can be accessed via this address:

$<$ https://archive.org/details/lartducuisinieroibeau>, accessed on $27^{\text {th }}$ December, 2017 .

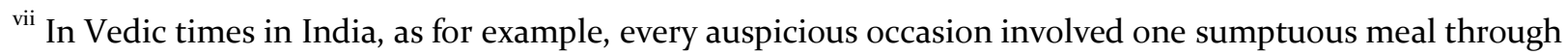
which the host was supposed to pay back all the 'debts' that he had, inescapably, incurred throughout his life; in Japanese culture O-tsukimi, the Japanese Harvest Moon Festival that dates back 1200 years, featured home-made food; in Chinese culture one can obviously refer to the glamorous Manhan Quanxi or The Manchu Han Imperial Feast that, during the Qing dynasty, featured marquee dishes and chefs from across the vast Chinese landmass.

viii Schehr, Lawrence R., and Allen S. Weiss. "Tractatus Logico- Gastronomicus." French Food: On the Table, on the Page, and in French Culture. Eds. Lawrence R. Schehr and Allen S. Weiss. New York: Routledge, 2001. P. 233-34.

ix This can be a very pertinent area of inquiry as 'cooking', personally or collectively approached, is basically a language-based activity that either follows a specific recipe which is a linguistic construct or is done according to specific instructions that make sense only in a co-operative linguistic field of mutually-shared codex of signification. Statistical models of co-operative game theory, Wittgenstein's conceptualizations on language games and Austin's ideas about performative language are some relevant theoretical constructs that can be invoked to clarify how cooking has emerged as a strategic, performative notion that embodies capital, both cultural and financial, in intricate ways.

${ }^{\mathrm{x}}<$ https://en.wikipedia.org/wiki/MasterChef_Australia>

Accessed on $28^{\text {th }}$ December, 2017.

xi <http://www.imdb.com/title/tt1433870/awards>

Accessed on $30^{\text {th }}$ December, 2017.

xii “MasterChef's Appeal Was Its Friends", David Penberthy, The Daily Telegraph. July 20, 2009. Newspaper Report.

$<$ https://www.dailytelegraph.com.au/news/opinion/masterchefs-appeal-was-its-friends/newsstory/bcfc67eec233ed3de8a164508664e5ffs

Accessed on $30^{\text {th }}$ December, 2017.

xiii <http://www.abs.gov.au/AUSSTATS/abs@.nsf/Lookup/3201.oMain+FeaturesıJun\%202009?Open> Accessed $30^{\text {th }}$ December, 2017.

xiv "MasterChef's Appeal Was Its Friends".

${ }^{\mathrm{xv}}<$ https://mumbrella.com.au/masterchef-grand-finale-down-more-than-500ooo-viewers-from-last-year460302>

Accessed on $30^{\text {th }}$ December, 2017.

xvi Ibid.

xvii “Raising the stakes!" Penelope Kilby, Mail Online. $5^{\text {th }}$ May, 2014. Newspaper Report. 
$<$ http://www.dailymail.co.uk/tvshowbiz/article-2619357/Rules-broken-stakes-higher-return-MasterchefAustralia.html>

Accessed on 3oth December, 2017.

xviii “Cooking up a Winning Sponsorship”, Mathew Glasner. Cross-Channel Marketing.

< http://www.experian.com.au/blogs/marketing-forward/2013/o2/11/cooking-up-a-winning-sponsorship/> Published on $11^{\text {th }}$ February 2013, Accessed on 3oth December, 2017.

xix $<$ https://twitter.com/masterchefau?lang=en $>$ (as on $10^{\text {th }}$ March, 2020)

${ }^{\mathrm{xx}}<$ https://www.facebook.com/MasterChefAU/> (as on 10 ${ }^{\text {th }}$ March, 2020)

${ }^{x x i}$ For a cursory yet satisfactory understanding of the global north/global south divide, the Brandt Line and Gini Coefficient and the unequal dispersion of wealth across different nations that has given rise to such uncomfortable yet inescapable binaries, consult:

"The Dimensions of the Divide: Theorising Inequality and the Brandt Line in International Relations". Nicholas Lees. Cambridge Review of International Affairs. 29th Jun 2012. 209-230. Web.

http://www.tandfonline.com/doi/abs/10.108o/09557571.2012.678300 >.

Accessed on 31 ${ }^{\text {st }}$ December, 2017.

xxii “The Regional Culture of New Asia: Cultural Governance and Creative Industries in Singapore”. Audrey Yue. Web.

$<$ http://nknu.pbworks.com/f/THE+REGIONAL+CULTURE+OF+NEW+ASIA+cultural+governance+and+cre ative+industries+in+Singapore.pdf $>$

Accessed on $31^{\text {st }}$ December, 2017.

xxiii What needs to be clarified at this point is that Sneja Gunew explores the 'principle' of 'official multiculturalism' practised both in Canada and Australia as striking a dubious balance among the dicey trifecta of considering the policy as a device to 'manage' cultural diversity, a cultural-political maneuver to facilitate participatory, pluralistic democracy and a subsuming, inclusive cultural drive to assimilate differences, thereby flattening uncomfortable sites of alterity in the name of an expedient, universal normativity. For a detailed reading, one may look at:

"Against Multiculturalism: Rhetorical Images in Multiculturalism, Difference and Postmodernism." Sneja Gunew. Multiculturalism, Difference and Postmodernism, Eds. G.L. Clark, D. Forbes \& R. Francis.

Melbourne: Longman Cheshire, 193.

${ }^{\text {xxiv }}$ It will be extremely relevant in this context to refer to the emergence of a new-fangled methodological field of 'food pedagogy' that seeks not only to address how 'food' and habits related to its consumption are undergoing rapid transformations across the globe; but also draws critical attention to the fact that 'food' as a category of consumption of 'produced' items deserve discursive analyses in terms of food practices, representations, narrativization, manufacturing, advertising, studying and so on. For a detailed understanding, one may look at:

Food Pedagogies. Eds. Rick Flowers, Elaine Swan. London: Routledge, 2016. Book. Print.

${ }^{x x v}<$ http://www.dictionary.com/browse/collusion>. Accessed on 01.01.2018

xxvi “What portion of the global economy is represented by the food and beverage sector?" Investopedia Academy, $2^{\text {nd }}$ June, 2015. Accessed on 01.01.2018.

$<$ https://www.investopedia.com/ask/answers/o6o215/what-portion-global-economy-represented-foodand-beverage-sector.asp\#ixzz52uvloIkg>

xxvii Ibid. 
xxviii In India, as for example, the way one makes money, if not directly dictated or manipulated by sociocultural mores or behavioural codex, is always scrutinized severely and the individual's along with his/her family's social acceptance rides, to a significant extent, on the way livelihood is earned. It is not always, therefore, solely about what one earns, but how one earns it that becomes pivotal in social situations. A pertinent illustration of this Indian reality is available in the 2012 small-budget movie Vicky Donor that told the story of a sperm donor who seems, except momentary hesitations, 'doing' just fine as long as the way he is making money isn't 'revealed', even to his own fiancé who would eventually be his wife.

${ }^{x x i x}$ Bell D and Valentine G, Consuming Geographies: We Are Where We Eat. New York: Routledge, 1997. Book. Cited in Food, Foodways And Foodscapes: Culture, Community and Consumption in Post-colonial Singapore. Eds. Lily Kong and, Vineeta Sinha. Singapore: World Scientific Publishing Co Pt. Ltd, 2015. Book. P.2.

${ }^{\mathrm{xxx}}$ Capital desperately needs normalization for its free flow as the 'normative' always has the maximum consumers or subscribers. For a rudimentary discussion on KIEO's promotion of free-capital-flow as a prerequisite of liberal economy and its critique, consult Global Political Economy by Theodore Cohn.

${ }^{x x x i}$ Participation in a game implies voluntary adoption of specific mutually-agreed-upon regulations where the established and external ideas of the 'norm' are integrated into the interactional field where 'game' as it is understood as a social/participatory phenomenon or activity is possible. A 'reality show' is in fact no different. External 'rules' are not only established and agreed upon, they are integrated into the fabric of the particular reality that constitutes the game. For a more comprehensive insight into how this happens, see

“The Juridification of Sport”. Ken Foster. University of Westminster - School of Law. 16 Nov 2011. Web. Accessed on 04.01.2017. < https://papers.ssrn.com/sol3/papers.cfm?abstract_id=1959909>.

${ }^{x x x i i}$ This idea of the 'production' of subjectivity in a neoliberal mould dominated by capital interplays and subtle negotiations of power in its various guises has been predicted by Foucault in his seminal conceptualizations on panopticon and surveillance, and his pronouncements do possess a rather eerie relevance in the context of the highly 'manipulated' and 'fabricated' framework of a reality TV show:

"He who is subjected to a field of visibility, and who knows it, assumes responsibility for the constraints of power; he makes them play spontaneously upon himself; he inscribes in himself the power relation in which he simultaneously plays both roles; he becomes the principle of his own subjection." (In Michel Foucault, Discipline and Punish: The Birth of the Prison. Vintage Books, 1977. P. 202-03.)

xxxiii For a more detailed analysis of Foucault's theorizations on panopticon and their relevance at a time when major media houses 'manufacturing' audio-visual entertainment across the globe show an unsettling obsession with the so-called 'reality shows', see

"Reality TV, Big Brother and Foucault." James Wong. Canadian Journal of Communication. Vol. 26, No. 4, 2001. Web. Accessed on 05.01.2018.

< http://www.cjc-online.ca/index.php/journal/article/view/1252/1247>.

${ }^{\text {xxxiv }}$ Marx's Capital: philosophy and political economy. Geoffrey Pilling. London: Routledge \& Kegan Paul, 1980. P.161-62. Book. Print.

${ }^{x x x v}$ For a more detailed, theoretical and Marxist analyses of the salient issues of subject-construction, commodity fetishism, capital distribution and labour-division, consult

Essays on Marx's Theory of Value. Isaak Illich Rubin. Translated by Milos Samardiija and Fredy Perlman.

Delhi: AaKar Books, 2008. Book. Print.

xxxvi Consuming Reality: The Commercialization of Factual Entertainment. Deery, June. London: Palgrave MacMillan, 2012. P. 145. Book. Print.

xxxvii Ibid, 18. 
xxxviii Taking part in a show like this involves different modalities of active participation that subsume the problematized prerequisites of sympathy for suppositions and stipulations regarding participant- and consumer-behaviour. This instance of 'individual volunteerism' begets a sort of 'sentimental capital' (Consuming Reality, 98.) that the market seeks to capitalize on. The study of emotion-driven financial decisions is called 'Behavioural Finance' and it is being accorded an incrementally-expanding importance in the discussions of how a consumer-choice is or more significantly, can be constructed.

While not very new, the field of Behavioural Economics is considered increasingly important in an age dominated by a steady stream of a wide array of data: images, audio-visuals, gif-s and a myriad of usercentric software interfaces that are embedded in handled devices. Adverts are becoming more 'directed', programmed after painstaking analyses of previous searches initiated or pursued by any 'target' user who might become a possible consumer. Analysts are paid a hefty amount of money to make sense of the 'digital chatter' going on about a particular product on social networks or popular online marketing sites that accumulate user-reviews. Statistically verified and substantiated data-points, gleaned in this way, allow for invaluable glimpses into individual preferences and thus increased efficiency in 'marketing'. For a detailed analysis of how this is achieved, consult:

Behavioral Economics. Cartwright, Edward. London: Routledge, 2011. Book. Print.

xxxix “Invaders, Illegals and Aliens: Imagining Exclusion in a 'White Australia”. Catriona Elder. Law Text Culture, Volume 7, Issue 1, Article 10. Web. P 223.

Researchgate. < https://www.researchgate.net/publication/30386286> Published on $18^{\text {th }}$ October 2015. Accessed on $8^{\text {th }}$ January, 2018.

${ }^{\mathrm{xl}}$ Fantasies of 'white Australia' have continued to be accorded a dominant space in the ethnic imagining-s of the Australian nation, not unlike the way this unitary-ethnicity-mould is constructed across the Continent or in the US.

xli "Compromised Narratives Along the Border: The Mason- Dixon Line, Resistance and Hegemony". Russ Castronovo. In Border theory: the limits of cultural politics. Eds. Scott Michaelsen and David E. Johnson. New York: University of Minnesota Press, 1997. P 201.

xlii Ibid. P. 202.

xliii We Are What We Eat: Ethnic Food and the Making of Americans. Donna R. Gabaccia. New York and Harvard: Harvard University Press, 2000. Book. Print. P. 8-9

xliv This extract should be instructive in this regard:

"Most SNSs (Social networking sites) create visible differences and specify different rules between personal profile pages and brand or firm-owner profile Pages. Contrary to mass media advertisements, brand profile Pages on SNSs provide information and allow viewers to respond to the firm's communications or posts... After the purchase has been made, SNS members may communicate their own experiences on the brand profile Page. The result is an ongoing process of interpersonal influence and online word-of-mouth recommendation." (Patrali Chatterjee, "Drivers of New Product Recommending and Referral Behavior on Social Network Sites. International Journal of Advertising, 30(1), 2011. P. 79.

xlv The word 'mechanism' is used in the absence of a more suitable word that can encapsulate the innumerable multiplicity of ways in which a myriad of factors including but not necessarily limited to capital, culture, representation, 'spectator-demands', media formatting, established structures of expectations, consumer-choices, personal tastes, cultural traditions and their 'commercialization', meticulous 'packaging' and the (in)flexible parameters of an elaborate game, - all interact and negotiate on so many dimensions.

xlvi Back in the 1940's American economist James Duesenberry clarified why and how that is the case; he had built upon Keynes' conceptualizations on social influences on consumption-decisions and further argued 
that a particular consumer, along with his choices, will inevitably be heavily influenced by consumption choices made by people with whom s/he has social or domestic relations.

xlvii Those interested in the mainstream discourse of Economics that has pioneered the study of social impact on consumer-behaviour may consult:

Macroeconomic Theory. Gardner Ackley. London and New York: Macmillan Library Reference, 1978. Book.

xlviii For a detailed discussion on 'food adventuring' and 'authenticity of exotic food-culture', consult:

Exotic Appetites: Ruminations of a Food Adventurer. Lisa Maree Heldke. New York and London: Routledge, 2003. Book.

xlix "Barred Bodies", in Baudrillard and Theology. James Walters. Oxford and New York: A\&C Black, 2012. Book. P. 107.

${ }^{1}$ The Consumer Society: Myths and Structures. Jean Baudrillard. London: Sage, 1998. Book. P. 132.

\section{References}

Abarca, M. E. (2006). Voices in the Kitchen Views of Food and the World from Working-Class Mexican and Mexican American Women. College Station, Texas: Texas A \& M University Press.

Ackley, G. (1978). Macroeconomic Theory. London: Macmillan Library Reference.

Ancient China's Legendary Banquet - The Manchu Han Imperial Feast. (1 $8^{\text {th }}$ January, 2012). Windhorse Tour Travel Team's blog. Retrieved from https://windhorsetour.com/blog/manchu-han-imperial-feast.

Austin, J. L. How to Do Things with Words. William James lectures on philosophy and psychology, Harvard University. (1975) Harvard: Harvard University Press.

Baudrillard, J. (1998). The Consumer Society: Myths and Structures. New York: Sage.

Benjamin, W. (2010) The Work of Art in the Age of Mechanical Reproduction. London: Prism Key Press.

Bourdieu, P. \& Wacquant, J. D. L. (1992) An Invitation to Reflexive Sociology. Chicago: University of Chicago Press.

Bourdieu, P. (1993) The Field of Cultural Production: Essays on Art and Literature. New York: Columbia University Press.

Cartwright, E. (2011). Behavioral Economics. London: Routledge.

Chatterjee, P. (2011). Drivers of New Product Recommending and Referral Behavior on Social Network Sites. International Journal of Advertising, 30(1). doi: 10.2501/IJA-30-1-077-101

Clark, G. L. Forbes, D. \& Francis, R. (Eds.). (1993) Multiculturalism, Difference and Postmodernism. Melbourne: Longman Cheshire.

Cohn, T. (2015). Global Political Economy. London: Routledge.

David, B. \& Valentine, G. (2006). Consuming Geographies: We Are Where We Eat. London: Routledge.

Deery, J. (2012). Consuming Reality: The Commercialization of Factual Entertainment. London: Palgrave MacMillan.

Duesenberry, J. (1949). Income, Saving, and the Theory of Consumer Behavior (Economic Studies: No. 87). Harvard: Harvard University Press. 
Elder, C. (2003). Invaders, Illegals and Aliens: Imagining Exclusion in a 'White Australia. Law Text Culture, 7(1), Article 10. Retrieved from http://ro.uow.edu.au/ltc/vol7/iss1/10.

Flowers, R. \& Swan, R. (2016). Food Pedagogies. (Eds.). London: Routledge.

Foster, K. (16 $6^{\text {th }}$ November, 2011). The Juridification of Sport. University of Westminster - School of Law. Retrieved from https://papers.ssrn.com/sol3/papers.cfm?abstract_id=1959909

Foucault, M. (1977). Discipline and Punish: The Birth of the Prison. New York: Vintage Books.

Gabaccia, D. R. (200o). We Are What We Eat: Ethnic Food and the Making of Americans. Harvard: Harvard University Press.

Geoffrey, P. (1980). Marx's Capital: Philosophy and Political Economy. Abingdon: Routledge \& Kegan Paul.

Glasner, M. (11 ${ }^{\text {th }}$ February, 2013). Cooking up a Winning Sponsorship. Http://www.experian.com.au.

Retrieved from www.experian.com.au/blogs/marketing-forward/2013/o2/11/cooking-up-a-winningsponsorship/.

Heldke, L. M. (2003). Exotic Appetites: Ruminations of a Food Adventurer. London: Routledge.

Japanese Festivals. Savory Japan. $\left(29^{\text {th }}\right.$ June, 2018). Retrieved from http://savoryjapan.com/learn/culture/festivals.html.

Kilby, P. (5th May, 2014). Raising the stakes! Mail Online. Retrieved from http://www.dailymail.co.uk/tvshowbiz/article-2619357/Rules-broken-stakes-higher-return-Masterchef Australia.html

Kong, L. \& Sinha, V. (2015). (Eds.). Food, Foodways and Foodscapes: Culture, Community and Consumption in Post-colonial Singapore. Singapore: World Scientific Publishing Co Pt. Ltd.

Kripke, S. A. (1982) Wittgenstein on Rules and Private Language: An Elementary Exposition. Revised ed. Harvard: Harvard University Press.

Lawrence, R. S. \& Weiss, A. S. (2001). (Eds.). French Food: On the Table, on the Page, and in French Culture. London: Routledge.

Lees, N. (2012). The Dimensions of the Divide: Vertical Differentiation, International Inequality and Northâ South Stratification in International Relations Theory. Cambridge Review of International Affairs, 25(2), 209-230. doi:10.1080/09557571.2012.678300.

Michaelsen, S. \& Johnson, D. E. (Eds.). (1997). Border theory: The limits of cultural politics. Minneapolis, Minnesota: University of Minnesota Press.

Oleschuk, M. (2012). Engendering Transnational Foodways: A Case Study of Southern Sudanese Women in Brooks, Alberta. Anthropologica, 54(1), 119-131. Retrieved from www.jstor.org/stable/24469621.

Penberthy, D. (19 ${ }^{\text {th }}$ July, 2009). MasterChef's Appeal Was Its Friends. www.dailytelegraph.com.au. Retrieved from foster.

Rubin, I. I. (2008). Essays on Marx's Theory of Value. Translated by M. Samardiija \& F. Perlman. (Trans.). New Delhi: AaKar Books.

Samios, Z. (25 ${ }^{\text {th }}$ July, 2017). Masterchef Grand Finale Loses Half a Million Viewers on Last Year as Ninja Warrior Wins Evening. https://mumbrella.com.au. Retrieved from mumbrella.com.au/masterchefgrand-finale-down-more-than-5000oo-viewers-from-last-year-460302.

Schehr, L. R. \& Weiss, A. S. (2001). (Eds.). French Food: On the Table, on the Page, and in French Culture. New York: Routledge. 
15 | The MasterChef Journey to Brain through Stomach: Food as Transnational Capital

Shamsian, J. ( $8^{\text {th }}$ June, 2018). 16 unforgettable quotes about life and food from Anthony Bourdain. thisisinsider.com.

Retrieved from http://www.thisisinsider.com/anthony-bourdain-quotes-2018-6.

Turvey, R. \& Duesenberry, J. S. (1950). Income, Saving and the Theory of Consumer Behavior. Economica, $17(68)$. doi:10.2307/2549507.

Walters, J. (2012). Baudrillard and Theology. London: A\&C Black.

What Portion of the Global Economy Is Represented by the Food and Beverage Sector? (2 ${ }^{\text {nd }}$ June, 2015). Retrieved from www.investopedia.com/ask/answers/o60215/what-portion-global-economyrepresented-food-andbeverage- sector.asp\#ixzz52uvloIkg.

Wong, J. (2001). Reality TV, Big Brother and Foucault. Canadian Journal of Communication, 26(4). doi:10.22230/cjc.2001v26n4a1252.

Yue, A. (March, 2006). The Regional Culture of New Asia: Cultural Governance and Creative Industries in Singapore. International Journal of Cultural Policy, 12(1), 17-33. doi: 10.1080/1028663060o613176 